\title{
Celebrity Chefs and Maculinities among Male Cookery Trainees in Vocational Education
}

\author{
Steno, Anne Mia; Friche, Nanna
}

Published in:

Journal of Vocational Education and Training

DOI:

$10.1080 / 13636820.2014 .927901$

Publication date:

2015

Document Version

Early version, also known as pre-print

Citation for published version (APA):

Steno, A. M., \& Friche, N. (2015). Celebrity Chefs and Maculinities among Male Cookery Trainees in Vocational Education. Journal of Vocational Education and Training, 67(1), 47-61.

https://doi.org/10.1080/13636820.2014.927901

\section{General rights}

Copyright and moral rights for the publications made accessible in the public portal are retained by the authors and/or other copyright owners and it is a condition of accessing publications that users recognise and abide by the legal requirements associated with these rights.

- Users may download and print one copy of any publication from the public portal for the purpose of private study or research.

- You may not further distribute the material or use it for any profit-making activity or commercial gain.

- You may freely distribute the URL identifying the publication in the public portal.

\section{Take down policy}

If you believe that this document breaches copyright please contact rucforsk@kb.dk providing details, and we will remove access to the work immediately and investigate your claim. 
Pre-print version of Accepted Manuscript (AM) of article published in

Journal of Vocational Education \& Training Volume 67, Issue 1, 2015

To link to this article: http://dx.doi.org/10.1080/13636820.2014.927901

To cite this article: Anne Mia Steno \& Nanna Friche (2015) Celebrity chefs and masculinities among male cookery trainees in vocational education, Journal of Vocational Education \& Training, 67:1,47-61, DOI: 10.1080/13636820.2014.927901

Department of Psychology and Educational Studies, Roskilde University, Roskilde

\title{
Celebrity chefs and masculinities among male cookery trainees in vocational education
}

Anne Mia Steno and Nanna Friche

\begin{abstract}
The purpose of this article is to examine how media-generated professional identities in the culinary sector are reflected in Danish male cookery students' narratives about their own identity, experiences and expectations about the trade. Hence, this study takes its starting point in studies that show how the broad popularity of the culinary profession - almost exclusively through male chefs seems to be attracting more male students to the cooking programme. The previous research indicates, however, that there is a risk of unfulfilled expectations when cookery students realise the hard work involved in working in a professional kitchen. It is this contrast between the media presentation and the practical reality of a profession like cookery that we wish to explore from the students' perspective.
\end{abstract}

Keywords: Vocational Education and Training; gender and learning; gender and educational training; history of education; gender - professional change

\section{Introduction}

The purpose of this article is to examine how media-generated professional identities in the culinary sector are reflected in the narratives of male catering trainees about their own identity, experiences and expectations of the trade. It contributes to other ongoing studies of the role of celebrity in informing young people's classed and gendered aspirations in complex ways (e.g. Allen and Mendick 2013). However, rather than a broad focus on more ubiquitous types of celebrity aspirations (pop stars, actors and royal personages), we introduce a focus on specific celebrity associations for vocational trainees.

This study therefore takes its starting point from research that has shown how the broad popularity of the culinary profession - almost exclusively represented through male chefs in Denmark - seems to be attracting more male trainees to catering programmes (Friche 2010). Previous research indicates, however, that there is a risk of unfulfilled expectations when catering trainees realise the hard work involved in working in a professional kitchen. It is this contrast between the media portrayal and the practical reality of a profession like cookery that we wish to explore from the trainees' perspective.

The purpose of the article is twofold: first, to identify celebrity chefs as accessible figures of professional chef identities that constitute part of the context to which male catering trainees must relate (Bureychak 2012); and second, to examine how 
trainees' perspectives are shaped by and in turn help to shape certain ways of 'doing masculinity' in education and training programmes in catering (Hjort and Nielsen 2003). Theoretically, we base our analysis on a conceptualisation of (culinary) masculinities as socially constructed in the tension between hegemonic masculinity and risk on the one hand, and marginalised femininity and compassion on the other hand (Connell 2012; Connell and Messerschmidt 2005; Mac an Ghaill 1994). Culinary professionalism is, we shall argue, imbued with this tension and interacts with masculinity in contrasting ways. We, therefore, make use of Colley et al.'s notion of vocational habitus (2003) as a way of illustrating how young men orient themselves in relation to these tensions (see also Broch 2012; Connell 1983).

The article builds on work carried out as part of a larger study on the intersectionality between studies of adolescents' gender and identity in secondary education in Denmark (Jørgensen 2013). By analysing empirical data on both cookery and catering trainees and media representations of chefs, the study integrates the reading strategies of cultural studies with the critical perspective of masculinity studies in educational research.

\section{Culinary training in the vocational field in Denmark}

The Danish Vocational Education and Training (VET) system is based on three main principles. First, it entails a dual-training principle; that is, periods of school-based learning alternating with periods of training in an enterprise (in this case, professional kitchens). School-based periods take up one-third of a full VET programme of approximately four years, while periods of workplace training take up two-thirds of the time. Thus, the dual-training principle is both a pedagogical principle and an organisational-institutional one. The norms and routines of the profession are inculcated in work placements, while specific technical skills and theory are introduced at school. Secondly, the dual system is based on a principle of social partner involvement, whereby social partners are involved in both overall decision-making about and daily operation of the VET system. Thirdly, it is founded on the principle of lifelong learning. This is achieved through the system's flexibility, which allows trainees the possibility of taking part of a qualification at a given moment and later returning to the system and adding to their VET qualification in order to access further and higher education. VET programmes are typically divided into two parts: a basic course, which is broad in scope and provided at schools, and a main course in which the trainee specialises in an occupation (e.g. catering, diet assistant) (Danish Ministry of Education 2013). The male trainees referred to in this article were attending a basic course at a vocational school.

The culinary VET programme qualifies trainees for employment in professional kitchens (e.g. restaurant, canteens and cafés). The core values of the occupation that the programme promotes are creativity (the creation of menus and innovation of new dishes) and attention to quality ingredients and hygiene (where the trainees draw on their senses such as colour perception, smell and taste). Furthermore, the trainees need to 'stay cool' and be able to manage the cooking of several hot dishes simultaneously without losing sight of the flow of starters, main meals, desserts, ingredients, cooking time, arrangement in plates, etc. School-based training aims to teach the theory of nutrition and hygiene as well as knowledge about ingredients. In the workplace, the trainees learn about the basic cooking of both hot and cold meals, 
control and quality assessment of ingredients, planning of menus, sales and customer service (Køkken Hotel \& Restaurant Uddannelse 2014).

\section{Constructions of masculinity and vocational habitus}

Media-generated masculinities of professional figures within the culinary sector are highly relevant to understanding the narratives - and especially the gender constructs - of male catering trainees, since these express a less explicit but nonetheless powerful hidden curriculum. Dominant symbolic and visual representations of masculinity can be regarded as mechanisms that set the framework for and support a hegemonic masculinity (Bureychak 2012, 141). This suggests that representations of celebrity chefs influence male catering trainees by illustrating particular, hegemonic, ideal types. Connell (2012) argues that only a few men perform and/or embody a prototypical, hegemonic masculinity in everyday contexts. But some fictional male characters or extraordinary male personalities (such as the successful celebrity chef) can become a symbol of such hegemonic masculinity. The adult man's body is staged discursively as a symbolic contrast to what is perceived as feminine, womanly, boyish and unmanly (Broch 2012).

While the concept of hegemonic masculinity may be criticised for being too narrowly determined and for ignoring competing masculinities, we still find this idealtype a useful concept to illustrate tensions in how trainees take up media portrayals of celebrity chefs in different ways and how this relates to gendered identities. When we refer to masculinity as a concept, three conditions are implied. Firstly, we are talking about masculinities in the plural, and we therefore mean that different masculinities are socially constructed and that perceptions of masculinity are associated with various social groups and cultures and can therefore coexist. Secondly, we consider masculinities as hierarchically constituted, which assumes that gender is placed in a social context where permanent struggles for hegemony take place and where some forms of masculinities are more dominant in relation to other forms of masculinities and femininities. Thirdly, we understand masculinities as collective characteristics: masculinities are cultural constructs or institutionalisations inflecting the individual's attempts to construct an identity as male or female (Hjort and Nielsen 2003, 17).

Connell has studied groups of Australian men for whom the construction of masculinity is in crisis as their sexual, social or structural position conflicts with historical traditional ideas about hegemonic masculinity $(2012,90)$. An example of this is young men who are affected by structural unemployment and who are therefore in conflict with traditional notions of the man as the primary breadwinner. This potential crisis is not very remote from the conditions that male catering trainees in Denmark risk experiencing in a trade with high unemployment rates in a context of economic crisis. It may be particularly relevant to investigate structures and identifications with particular types of masculinities in such crisis situations, since these may lead to confrontations with classical hegemonic images or to new-idealisations thereof. Ensuing challenges to traditional perceptions of masculinity can result in men orienting themselves towards feminine values such as caring and empathy, while a new-idealisation can be observed as men who cultivate the hegemonic, welltrained and strong masculine body and emphasise aggression, confrontation and competition (Connell 2012, 123). 
Building on this dual tendency, we draw here on a contrapuntal distinction between risky behaviour and compassionate rationality, inspired by a study of masculinity in rescue work (Weinestål, Bondestam, and Berg 2011). Exposing oneself to risk, experiencing risk or participating in violent situations is often linked to masculinity constructs. Based on the heroic figure as essential to masculinity constructs, firefighters, for example, must be strong, intelligent and brave. But this hero status also depends on exercising compassion to the victims they rescue. This compassionate rationality constitutes an essential counterpoint to risky behaviour. In the catering business, the concept of risk is relevant too, since working environments in professional kitchens are often characterised by a high tempo and by the handling of extremely hot objects and liquids, sharp knives and other tools that risk damaging the chef physically and mentally. On the other hand, compassionate rationality is represented by the care that the chef must take in preparing food nutritiously and hygienically.

Within this field of tensions and expectations about chef trainees doing masculinity in legitimate ways, we apply Colley et al.'s notion of 'vocational habitus' (2003). This concept has been developed in respect of dynamic learning processes of becoming (a skilled worker) which are expressed in the unwritten or hidden curriculum, rather than the explicit curriculum. It is, therefore, relevant in analysing how the young men in our study navigate between different expectations and narratives: being willing to take risks and to show personal bodily strength and fortitude; but also talking about and showing compassion for others.

Vocational habitus is about 'what makes the right person for the job' (Colley et al. 2003, 14) and is, therefore, seen as a way of becoming, a dispositional transformation governed by possibilities and limitations entailed in a particular vocational field. In that sense, it draws on Bourdieu's concept of habitus and field (1995) and Lave and Wenger's notion of communities of practice (1991). The young men already are something when they enter the chef programme, but they are also becoming something in the various fields they engage with. This development of identity and membership in a field, or community of practice, is a central aspect of vocational learning. It is important to highlight how these fields are both multifaceted and internally filled with different tensions as described above. As we will expand upon in the analysis, our data suggest an existence of tensions between different expectations and narratives, not only in the VET programme itself, but also in the workplace and the wider landscape of media portrayals of the professional chef. A school is never an island, but as Colley et al. put it: "VET may be different from learning solely in the workplace, but it is deeply influenced by patterns of employment and social role allocation that are established outside the college' $(2003,488)$. There are of course even more diverse contexts to account for, such as peer group relations and family ties that inform and influence trainees, but the in-depth analysis here focuses primarily on the VET programme and media images. Vocational habitus is neither a unitary nor an essentialistic concept, but rather 'contains important contradictory tensions which the learner must negotiate' (Colley et al. 2003, 485). One example of these contradictory tensions is the way in which an idealised notion of what it takes to be a health worker - compassionate caring - conflicts with the realities of practice, where detachment and distancing oneself is also needed as a coping strategy (Colley et al. 2003, 480-482). The idealised habitus of loving care is not fully realisable in practice, and as a result trainees must orient themselves to both idealised and realised ways of being. Vocational habitus is, therefore, neither a 
unitary nor an essentialist concept, but rather 'contains important contradictory tensions which the learner must negotiate' (Colley et al. 2003, 485). There is, then, a need for complexity rather than polarisation in understanding the identity-work and transformation of vocational habitus, 'as a process of orientation to, rather than adoption of' both idealised and realised dispositions (Colley et al. 2003, 485).

\section{Method and empirical basis}

This article builds on work carried out as part of $\mathrm{PhD}$ and postdoctoral projects, respectively, which are related to studies of adolescents, gender and identity in secondary education. Empirically, the article has two points of departure: a review of media representations of chefs and qualitative data on cookery trainees.

Through a systematic review of Danish newspapers, food programmes, cookery books and food magazines, we identified two stereotypical ideal-types of the chef that exist across the different media. We will present the two ideal-types in a later section. In order to ensure broad representation, we have searched for articles with the keywords 'kok*' and 'mad*' ['chef' and 'food'] in Infomedia's database from the period 1 November 2008 to 1 November 2012. We searched the categories 'radio spots \& TV spots' and 'national newspapers'. The same keywords were used in the site 'Google Image'. In addition, we used the site 'Google' to search for Danish cookery books and magazines with the criteria 'kogebog*', 'madmagasin*' and 'kok*' ['cookery book', 'food magazine' and 'chef']. Not all of the various celebrity chefs represented in this analysis are certified chefs (in a VET context) as several are self-taught and have educational backgrounds in completely different areas. For example, the Danish chef Claus Meyer holds a master's degree in political science. However, these chefs are included in our study because they are very visible representations of chef identity figures in the Danish media. As we will discuss later, although the different backgrounds of these chefs reflect diversity in forms of professional qualifications and pedagogic authority, the ideal-types are the same across different media. But given the constraints of space in this article, we focus on TV celebrity chefs alone.

The empirical data in this article are drawn from a longitudinal study across four youth education programmes (one class from an upper secondary school and one from the VET programmes in business/commerce, auto mechanic and culinary, respectively) involving a total of 92 students. From that sample, 24 students $^{1}$ have been selected as core informants and have been followed both in and outside of school for a period of two years (see more about this project at www.drible.dk). Indepth individual qualitative interviews have at present been conducted twice with the core group, and in addition focus group interviews have been conducted with the whole group. Extensive participatory observation and classroom observation have been conducted at all four schools in periods varying from two to seven weeks at each school. The aim of the study is to integrate a twofold view on both the student perspectives (student experiences and expectations) and institutional logics. The ethnographic and interpretive approach is related to national cohort studies and broader tendencies, and discussed in relation to the logics and sentiments of the schools. The broad contextualisation is aimed at clarifying that although we only have space in this paper to focus on three boys, our thinking has been shaped in the light of data and analysis across the project. The contextualisation in broader 
tendencies is not an excuse for using an in-depth case study, as we find the ethnographic and interpretative approach relevant in its own right (Flyvberg 2006).

Thus, here we focus on three male trainees in the culinary programme. These three young men are all enrolled in a basic course at a vocational school in Denmark, in a class with a total of 21 trainees, 12 of whom are male. At the time of the interviews used in this article, the trainees have had no experiences of apprenticeship in a professional kitchen, but two of the three have worked voluntarily or had part-time jobs in kitchens. The three were selected because their narratives represent widely entrenched positions among the group of trainees; i.e. personal experience with other uncompleted VET programmes and dropout, experience with the culinary business from job training or family (social background). In order to ensure the trainees' anonymity, names and localities have been changed or left out.

\section{Chefs in the TV media}

In Denmark, the TV kitchen as a phenomenon dates back to the 1960s, but has experienced a resurgence since 1999 when the young Briton Jamie Oliver was broadcasted on Danish television and had success with an unpretentious style of cooking for friends and family. Oliver's appearance on TV was the start of a new trend of food programmes, such as Danish versions of the international concepts of 'Masterchef' and 'Hell's Kitchen', set in large restaurant kitchens with focus on competition, time limits and high-quality gourmet cuisine. But the trend also includes originally Danish programmes such as 'Spise med Price' ('Dining with the Price Brothers') with Adam and James Price, two heavy-set brothers known for their fatty recipes and corny jokes. ‘Meyers Køkken’ (Meyer's Kitchen) with Claus Meyer, is a programme focused on sustainable 'slow food' set in an outdoor kitchen or in the countryside. 'Mad der holder' (Substantial Food) is fronted by Camilla Plum, a rustic country woman who cooks surrounded by children and gardeners in her open kitchen. 'Nak og Æd' ('Kill and Eat') presents the chef Nikolaj Kirk, who goes hunting in the woods and prepares meals on an open fire. Along with cookery programmes on TV, several food magazines have also been launched and newspapers have paid attention to the culinary business in their lifestyle and culture sections.

All this reflects an increased attention to the culinary profession from the media. The crowning of the Danish restaurant NOMA as the world's best restaurant by Restaurant Magazine in 2010-2012, and the Danish chef Rasmus Kofoed's gold medal victory at the Bocuse d'Or ${ }^{2}$ in 2011 supports this trend. A key question arises from this trend: what images of the culinary profession and what available chef identities are generated by all this attention? Our comprehensive review of Danish newspapers, food programmes, cookery books and food magazines identifies two stereotypical identities for the culinary profession, promoted across the various media. They are on the one hand the socially responsible chef; and on the other the exceptional chef with a 'hard' character and a fiery temper. We go on to explore these representations in greater depth.

The celebrity chef as socially responsible entrepreneur

Central to this first professional identity is a social responsibility that focuses on environmentally sound food production, well-prepared food and quality ingredients, and sustainability in terms of nature and climate, as well as educating the audience. 
In this personification, the celebrity chef is someone who prepares food step by step in order to demonstrate and explain the essential features of handling raw materials, preparation and flavour to the audience. The Danish chef and entrepreneur, Claus Meyer, is a typical example of the socially responsible celebrity chef who seems to take on the character of a missionary by talking about cooking as a vocation, about 'bringing light into the darkness' and about the need for an outright food revolution in Danish private households (to get rid of all the industrially produced canned food and fast food). Once a chubby young man, he is now a well-trained missionary of holistic living, often portrayed cooking while standing on the beach as the sun sets. $\mathrm{He}$ is beyond a mere chef; he is an entrepreneur with multiple restaurants, bakeries and delis. He owns the award-winning restaurant NOMA, and is famous for spreading knowledge on organic foods and promoting locally grown ingredients from small islands in Denmark. Furthermore, he attracts and leads crowds of people in big venues for 'knead the dough' seminars. He is involved in numerous social awareness projects, such as cooking with prison inmates to give them a second chance in life. He thereby holds a position as a holistic educator of the public and a working-class figure. As Hollows and Jones have described, with reference to the British chef Jamie Oliver, the celebrity chef transforms the blue-collar worker into a more civilised and responsible person who cooks substantial and sustainable food for his or her family based on quality ingredients and concerns for health (Hollows and Jones 2010). This culinary identity promotes a culinary culture and philosophy based on season and location. Ethical behaviour and struggles of local vs. global food and interests are driving forces. It is a movement and it is normative: the differences between good/evil and unhealthy/healthy are extremely sharp. This missionary approach to food, nature and ingredients can be seen as an expression of compassionate rationality, driven by the desire to improve people's eating habits and promote the well-being of the working class. In addition to Meyer, other celebrity chefs such as Camilla Plum and the Price brothers belong in this category. This means that the category includes both male and female chefs. The Price brothers in particular are known for their mischievous glances, flushed cheeks, playfulness and sarcasm when adding yet another lump of butter to the Bérnaise sauce (Leer 2013). But their extra dollop of butter is organically produced which makes it a sustainable, highquality ingredient. Thus, neither Meyer, Plum nor the Price brothers preach abstinence in the name of health. They represent a holistic education promoted through quality ingredients, love of food, playfulness and compassion for the local environment and social relations. In an international context, celebrity chefs such as Jamie Oliver and Hugh Fearnley-Whittingstall belong to this category. It is characteristic of this ideal-type that the chefs are mostly self-made. Both Meyer, the Price brothers and Plum are originally from the academic field. This may indicate that civilising the working class is an upper middle-class ambition: it has a moral rather than a purely educational aim. Chefs in this category tend to represent an understanding of qualifications informed by compassion and they represent a rather anti-authoritative and non-conformist pedagogy in respect of educating the public.

The celebrity chef as the exceptional chef with a fiery temper

A main characteristic of celebrity chefs in this category is that they strive to perform, to win, to achieve high ends and to be the best among their peers. They are willing to sacrifice themselves for the cause and they leave nothing to chance. For 
these chefs the perfect meal, its composition, flavour and taste is the second-to-none goal. They are like elite sport competitors, as it requires extreme determination, competitive spirit and a willingness to take risks to perform at this level. For celebrity chefs in this category, the concept is usually that the chef monitors the cooking in a restaurant that is on the verge of bankruptcy, after which changes are initiated by means of violent gesturing and strong language. Specific examples are the Danish chefs Wassim Hallal and Bo Bech who star in 'Hell's Kitchen' and 'Med kniven for struben' ('With a knife at the throat'). Both of the chefs in these programmes are often portrayed in front of intense fire and deadly sharp knives. In an international context, chefs like Gordon Ramsey belong to this group.

This category of chefs is represented solely by men, who use their expertise to improve the less-skilled or less-experienced chefs' performance in the kitchen. However, this does not imply that there are no female chefs who are high performing. They do exist, but like the Danish chef Mette Gassner who won the title 'Chef of the Year 2011', they tend to highlight the team's joint effort rather than individual performance. This gendered difference may be a specific Danish phenomenon, as female celebrity chefs, such as Delia Smith and Nigella Lawson are strong media images in the UK. However, this is not the case in Denmark, where the female celebrity chefs in our review either promote the collective effort, as is the case with Mette Gassner, or belong to the caring chef category. Exceptions are female confectioners who have experienced a boom in the media in Denmark, but who we have left out of this article due to the lack of space.

Since perfect flavour is central to these chefs' understanding of professionalism, the end seems to justify the means; that is to say, risks must be taken in the kitchen in order to achieve the perfect meal. This is typified by the Danish chef Rasmus Kofoed, who lost his sight in one eye because of the cooking activity during the Bocuse d'Or in 2011, but carried on regardless and won the gold medal. The risk of blindness could not dissuade him from pursuing the perfect meal and the victory. Examples like this place risky behaviour in the centre of this professional identity of the competing chefs. Another characteristic of this category of chefs is that they are certified and hold high standards regarding qualifications. In TV programmes involving amateur chefs or public restaurants, a highly authoritative pedagogy seems to be the main way to improve and change the behaviour of the participants. In Hell's kitchen, the participants are blamed and yelled at if they fail to perform. In the programme 'With a knife against the throat', the set-up is based on failed restaurants where a celebrity chef intervenes. The participants are under huge pressure from the risk of bankruptcy. In other words, the cooking is more than merely food and taste; it is a question of survival.

Spanning the two culinary identities of the celebrity chefs, the male (and female) chef appears as a competent body, professional and with a high degree of culinary professionalism in relation to knowledge (of ingredients, chemistry, roasting times, colour composition, taste nuances, texture) and manual dexterity (in the handling of sharp knives, slicing and filleting, hot liquids, dishes and pots, whisks, flaming, presentation). A niche is the chef with the scarred body, which signals a particular form of masculinity, characterised by native tribal cultures, fire and flames, devil/hell, tattoos, death metal, hunting and outdated hunting methods, weapons (large knives, harpoons, spears, etc.), piercings, shaved heads, marked and visible muscles and nudity. Examples of this category include Thomas Rode Andersen, masterchef at a highly ranked restaurant in Copenhagen and also front figure in a new Nordic 
‘paleo' movement which promotes Stone Age cooking focusing on vegetables, berries, nuts and meat. He is often portrayed with a naked torso, flashing a 'six-pack' of abdominal muscles and a number of tribal tattoos. Another example is Nikolaj Kirk from 'Nak og Æd' ('Kill and Eat'), who is famous for travelling to distant and foreign places in the world, cooking locally and integrating himself in local culture. $\mathrm{He}$ is often portrayed sunburned, with a Native American hairstyle, cooking around a campfire. The male body is masculine, precisely by being, and being perceived as, competent and strong, by taking up space in both a physical and a psychological sense (Connell 1983). It is this ideal-type image of masculinity that these chefs with their exposed and scarred bodies represent. While Thomas Rode represents the exceptional chef, Nikolaj Kirk represents the movement of culinary sustainability, awareness of climate, location and season. Thus, the professional chef identity as a performing body is not limited to a single celebrity chef category, but may also include elements of both ideal-types.

Chefs and gender identities among male cookery trainees

Based on empirical data extracts from group interviews with male cookery trainees, we will now focus on how cookery trainees relate to the identity of a culinary professional. The analysis is based on two themes: the young men's perception of celebrity chefs and expectations for their future in the catering business. Hereby, we gain an insight into the motivation for their choice of profession and of their different perceptions of culinary expertise. The focus in this article is on three young men: Dennis, Bo and Christian, who are, respectively, 18, 25 and 19 years old and attend a basic programme of chef training. All three trainees are 'returners', that is, they already have one or more uncompleted programmes behind them, and therefore tend to be older than trainees in other basic vocational educational programmes. As pointed out by Jørgensen and Juul (2010), recruitment for chef programmes in Denmark is generally from returners and older trainees, so the three young men in our study are not extraordinary in that regard.

Bo has studied history at university, has been a sailor and has worked as a craftsman. He states that the cookery training programme is his last chance to become certified and skilled, to 'get things together' as he puts it, which alludes to his advanced age compared to the other trainees. Dennis is academically the best performing trainee of the class. After the first three modules of the basic programme he has a very stable attendance, which is unusual in the class, where poor attendance is common. Before this course, Dennis was enrolled in another VET programme, but dropped out. Previously, he wanted to be an ambulance driver because he has seen programmes on television about the job and wanted to 'help and save lives'. Christian is one of the few members of the class that has completed secondary education, the higher preparatory assessment (gives access to higher education) and then spent three months in unpaid training in a restaurant. During the initial modules of the basic programme, Christian performed significantly better in the kitchen than the rest of the class.

Role models and motivation: the compassionate chef

Dennis: I don't know if I really have any role models. But, you know, you watch the various food programmes that are shown (...) Masterchef, for example. Where, you know, I think it's really great (...) when some chefs help people move on with their stuff. I like them. 
Dennis mentions Masterchef as a sort of role model, but it is neither the competition or the high qualification he stresses, but rather the social responsibility and the helping of others. When Dennis talks about 'helping' others in relation to the chef programmes, he seems to be talking about the category of chef who acts as an educator and social entrepreneur. It is not Masterchef as elitist hero who is in focus, but the compassion and support for others and being part of a transformation of the other - 'helping people move on with their stuff'- that is. This can be related to Hollows and Jones' studies of celebrity chefs in Britain (2010), where they argue that, by cooking and teaching about healthy food, chefs engage in a civilising and transformative process with the audience.

In this sense, Dennis's motivation of cooking with compassion is in line with an ambition he had earlier in life, to become an ambulance driver. The idea of the chef as a social entrepreneur is also emphasised by Christian:

Christian: I don't have any particular [role models]. I think that all those who choose to cook for others are great people. That they bother to think about others. It's ... [Shakes his head]. All the chefs who are doing it for the money, they ... Those who have the desire to do it for others, they are the ones who should do it, because they are the ones who make the best food.

Christian's remarks seems to suggest that being a good chef, that is, one who 'does something' for others, is equal to being a good human. But it implies a negation at the same time: a chef who is not acting out of compassion is not only a bad cook, but also a bad person. Christian does not put the idea into words, but pauses in his flow of speech and shakes his head to indicate how he perceives it wrong to cook for money alone.

Bo: [has previously mentioned Fearnley-Whittingstall as a role model and he elaborates]: It is something self-sufficient, for example. Well, he has a farm, he has a café. He has it all, or at least what I would certainly like myself. He gets to walk in his garden and says whatever he wants. And all these kind of small things. He enjoys life, at least it seems that way when you look at him. $\mathrm{He}$ enjoys life, and he is happy, and he has energy for it all. I want that too. I would really like that. I would also like to have a calm life and not have to stress like everyone else. They are fantastic cooks. Really cool. But I wouldn't like that pace.

Like the other boys, Bo talks warmly about the category of chefs who are socially responsible entrepreneurs, and compared to the other two, he expands the idea of compassion into a broader perspective of social responsibility and sustainability. His statements about a life without stress and about subsistence farming are references to the good, simple life and a rejection of a consumer and non-recycling culture. He acknowledges the aspiring chefs, while simultaneously denying that he wants to pursue such ambitions.

In all of our data, a recurring theme is how the boys identify cooking with compassion. Being a good chef is not about celebrity and fierce competitive spirit. The above two references to Fearnley-Whittingstall and Masterchef are single cases of celebrity chef references in the data as well as in these three specific narratives from Dennis, Bo and Christian. The celebrity references are in both cases made with regard to social responsibility rather than performance and competition. The fact that Bo specifically rejects the fast-paced, competitive culture of the culinary profession 
is interesting compared to his own life situation. When Bo, as illustrated below, dreams of having a farm and being self-sufficient, and when he speaks of the catering VET programme as his last chance to 'get a grip on things', this may represent an experienced pressure to support his family. Thus, he identifies with a traditional gender approach to masculinity and the man as breadwinner. Bo does not appear to believe that he has the opportunity of any further educational choices or experiments with the culinary profession's competitive culture. He has a duty to his family. From that perspective, the identity of the professional chef as a compassionate person, becomes a way, via own farming, own production and own cooking, of conforming to the traditional masculine role of a breadwinner. For Christian, social responsibility is not concerned with taking care of and supporting a wife and children. When he speaks approvingly about cooking and culinary professionalism as compassion and social mediation, it is about something else: a way of being social. To him, cooking works as a social 'glue' between people. It is a way of caring, and thereby it creates communities. This point becomes even more visible in the following section.

Expectations and culinary professionalism: relationships and community

The French sociologist Bourdieu (1995) has pointed out how the close link between identity and consumption gives food an essential role in society; food and cooking communicate our public identity. It is interesting in this context to contemplate how, among the male cookery trainees, cookery is perceived as a way of taking care of other people, a way of showing love, even intimacy with your close relatives, family and friends. In line with Bourdieu's findings, this suggests a cultural norm that if you make delicious food and well-prepared meals based on healthy, home grown, organic ingredients, then you are a caring, responsible, good and decent person: a person other people can rely on and be supported by. This point is reflected in the boys' dialogue on expectations for their future:
Bo:
I have a dream about buying a farm in France and being able to engage in agriculture and have a Bed \& Breakfast. That would be nice.
Interviewer: What about you Christian?
Christian: Well, I don't feel that I have to own anything. I just want to work in small places, because it is more pleasant, and it's more personal ... there is a larger social circle. There are some regular customers, and they like the food so much that they come straight out with it, and say: 'Thanks very much for the good food! It could be a little better if you just add a little more spice next time.' In that way you get per- sonal feedback and not only when the waiter says: 'It's wrong. It's wrong. It's wrong. The customers say'. But that they come and say it themselves.
Dennis: $\quad$ Yes, probably the same as Bo with that joy when you might see that people think it is good and delicious food. It is about being able to see that it's damn good, what you yourself are making for them.

Bo's statement reinforces the dream of being self-sufficient and self-supporting, and living in a harmonious and sustainable relationship with nature. Christian's statements elucidate his previous reflections on the links between compassion and food, by emphasising the personal, intimate and local. He emphasises the value of knowing his guests, and it is easy to see associations with a private kitchen at home. This 
emphasis on cosiness, intimacy, the social circle, regular customers and their praise of food and the personal feedback contrast with Christian's description elsewhere of his friends as 'people who let you down'. In this respect, Christian's future hopes of an identity as a professional chef are linked to dreams of gaining access, through his cooking, to sincere, loyal and stable social relationships that do not disappoint or fail him. For Dennis too, it is the joy of preparing food for others that is paramount. A joy of cooking that, although not quite as directly formulated as Christian's, can provide access to feelings of acknowledgement and praise from others.

The body in the kitchen and notions of homogeneity

Although the narrative of the caring chef seems consistent in the above example, this unambiguous presentation is challenged in practice in the school kitchen, and this seems to imply an interweaving of different ways of doing 'chef' and masculinity that challenges the hierarchy of the dichotomies. In our participatory observations in the school kitchen, we noticed how the boys' bodies make themselves noticed in the room in different ways. The kitchen marked and scarred the trainees' bodies by burning their hands and arms. We noticed that in the kitchen, performance-oriented culinary professionalism exists as risk-taking and willingness to endure pain, and this is highlighted among the boys as they work together - especially in contrast to the girls. Dennis receives a severe burn on his hand one day, but he continues to work, while with the support of the other boys who are standing around him, he repeatedly affirms that he cannot be put off by that kind of thing, unlike one of the girls, Rikke. Dennis let everyone know that he will not 'disappoint' them by failing to deliver the food on time, just because he has burned himself. This emulates the way in which Rasmus Kofoed continued his competitive cooking at Bocuse D'Or in 2012.

Observations like that are not unique, and they indicate that the male cookery trainees' behaviour in the kitchen reflects an orientation towards the culinary profession's culture of performance and competition. It is important to emphasise that we do not make the statement that girls cannot endure pain whilst boys can - but only to point out that a gender-contrasting notion seems to figure among the boys in regard to the idea of enduring pain.

In a restaurant kitchen, all food production is subject to time pressure, a performance pressure that we observed being reflected in the school's trainee kitchen. As the trainees perform in the kitchen shoulder by shoulder they monitor each other: how does the boy next to me cut that potato? How long does he fry the meat for? How should it look and feel when well done? Hence, a competitive culture, like the one in professional kitchens, can be observed in school kitchens. In the kitchen, the trainees behave in line with classical and traditional perceptions of the chef's craft, and as it is to some extent presented in the media: with a high pace, extreme focus on timing and a risky working environment. Our observations relate to a point made by Connell (2012) that masculinities are of relational, dynamic and contextual nature. The boys do male chef differently in different contexts: in interviews as compassionate individuals and in the kitchen as high-performing chefs. Furthermore, the data seem to suggest that while the trainees talk about how culinary work focuses on the image of the caring chef, the realities of the work (especially its dangers) call forth associations with the 'scarred/heroic/macho chef'. What is crucial here is that these two ways of doing masculinity and doing chef trainee construct a tension 
which these young men must navigate. Walking the line between these contrasting images of the chef is essential to successful integration into (or orientation to) the vocational habitus. If a young man is too caring or nurturing, he is unlikely to survive in the adrenalin-fuelled environment of the commercial kitchen. If he is too macho and too risky, he is not able to maintain the fundamental care and hygiene necessary in a kitchen, and might, therefore, cause sickness among customers by serving food not properly prepared. These contradictory tensions which need to be navigated are parallel to the findings of the case studies of Colley et al., who point out that VET trainees must orient themselves to 'both the idealised and realised ways of being, for the one mitigates the other' (2003, 485).

Although a number of the male cookery trainees have tattoos, none of them physically resembles the ideals espoused by the celebrity chef category of 'the exceptional chef with a fiery temper' whose bodies tend to take up space and attention in the media. The boys are all very different in height and size, and have different educational backgrounds. Despite this diversity, the boys in this analysis seem to perceive themselves as part of a homogeneous gender community. As Christian points out (with applause from Bo and Dennis):

Christian: Girls very quickly form cliques. I've also observed this, when I was in primary school, that the girls gathered in groups, where they have a common leader. I've observed the same thing here; they do it the same way. They sit in groups where they feel they belong together. Whereas the boys, well, we're all at some level the same kind of boys, we just think differently sometimes. So, we just sit together. (...) Most boys play football and computers and sports in general ... we are a common boy. Or common-boys.

Naturally, boys' communities are about much more than distancing themselves from femininity, but it is interesting how the male cookery trainees seem to agree that boys are identical, while girls are different. This point is particularly relevant in a business where, at least in the media, the focus is on (male) individualists, the extraordinarily talented and strong chef and body, or the socially responsible educator. In this context, the statement above appears to identify with a point made by Connell (1983) that very few boys can live up to the ideals of masculinity regarding strength and skills, and that young men in particular struggle with their own masculinity. The fact that the male cookery trainees refer to themselves as a homogeneous 'common-boy' group and their future identity of professional chefs as a compassionate position makes us suggest that the experience of not living up to the ideals of the masculine body creates a need for homogeneity, where gender is located in the community and in the group of boys. As previously described, a crisis in the experience of masculinity may result in men who emphasise the importance of feminine values such as compassion and empathy. Another result of such crisis experience may be to promote the hegemonic, to train and strengthen the masculine body and emphasise the importance of confrontation and risk. The risky behaviour and the body's strength and markings become visible in observations in the kitchen (in contrast to the oral narratives). This suggests that, in parallel with the emphasis on compassionate rationality among the male cookery trainees, there is a new romanticising of the traditional masculine working hero and the breadwinner role. In the kitchen, it is not compassion for the injured person that is paramount, but the strong man who carries on without taking pity on himself and who does not let down his peers. 


\section{Conclusion}

Even though there exists a general understanding of a connection between the increased popularity of celebrity chefs and the rising number of applicants for cookery VET programmes in Denmark, our analysis shows that media-generated chef identities are identifiable among the trainees, but not as directly as idols or role models. Yet, the different categories of celebrity chefs still exist as a point of reference and a physical effort among the boys in our study as a bodily practice of the profession and a becoming of the professional chef. The competent male body, as a symbol of high-level professionalism, includes elements of both risky behaviour and compassionate rationality, and can thus be found among the trainees. But it is not the media-generated chef identities alone that motivate the boys to participate in the VET programme. Rather, it is the profession as an opportunity to show compassion for other people. This suggests that a tough business like the catering business (and the training for it) may serve as a place for young men and boys to construct a space for acting out compassion in legitimate ways.

Vocational habitus is a way of becoming, a transformation governed by possibilities and limitations. For the young men in Danish VET in our study, becoming a professional male chef implies on the one hand the limitations of living up to ideals of the masculine body. On the other hand, the catering VET programme also represents possibilities of acting compassionately. This contradictory tension of limitations and possibilities is what male chef trainees must be able to navigate within across the different fields that VET trainees engage with. At school, imitations of 'real life' risky environments in professional kitchens are demanded of trainees. At the same time, when confronted with professional chef figures in the media, trainees are drawn to those representing social responsibility, sustainability and compassion for others. The vocational habitus of emerging male chefs is thus based on rather idealistic expectations for a future in this business. Such highly idealistic expectations might be difficult to actualise in apprenticeship and after completion of the entire programme. As such, they suggest that for these male trainees the real life and hard work of the culinary business is yet to come.

\section{Notes}

1. Eight students from the upper secondary school, six students from the VET programme in auto mechanic, six students from the culinary VET programme and four students from the VET programme in business/commerce.

2. Bocuse d'Or is an international and prestigious competition in the culinary arts. Bocuse d'Or has been held in Lyon every second year since 1987 and is named after the French chef Paul Bocuse.

\section{References}

Allen, Kim, and Heather Mendick. 2013. "Young People's Uses of Celebrity: Class, Gender and 'Improper' Celebrity." Discourse: Studies in the Cultural Politics of Education 34 (1): 77-93.

Bourdieu, Pierre. 1995. Distinksjonen. En sosiologisk kritikk av dømmekraften [Distinction: A Social Critique of the Judgement of Taste]. Oslo: Pax Forlag A/S.

Broch, Trygve B. 2012. "Masculine Men Playing a Women's Sport? Norwegian Media Representations of Male Handballers." Norma Nordic Journal for Masculinity Studies 7 (2): 183-198. 
Bureychak, Tetyana. 2012. "In Search of Heroes: Vikings and Cossacks in Present Sweden and Ukraine." Norma Nordic Journal for Masculinity Studies 7 (2): 139-159.

Colley, Helen, David James, Michael Tedder, and Kim Diment. 2003. "Learning as Becoming in Vocational Education and Training: Class, Gender and the Role of Vocational Habitus." Journal of Vocational Education and Training 55 (4): 471-496.

Connell, Raewyn. 1983. Which Way is up? Essays on Sex, Class and Culture. Sydney: George Allen \& Unwin.

Connell, Raewyn. 2012. Masculinities. Great Britain: Polity Press.

Connell, Raewyn, and James W. Messerschmidt. 2005. "Hegemonic Masculinity. Rethinking the Concept." Gender and Society 19 (6): 829-859. www.sagejournals.com.

Danish Ministry of Education. 2013. Initial Vocational Education and Training Programmes. http://eng.uvm.dk/Fact-Sheets/Upper-secondary-education/ /media/UVM/Filer/English/PDF /Fact\%20sheets/101221_Initial_Vocational_education_and_training_programmes.ashx.

Flyvberg, Bent. 2006. "Five Misunderstandings about Case-study Research." Qualitative Inquiry 12 (2). www.sagepublications.com.

Friche, Nanna. 2010. “Erhvervsskolers evalueringspraksis: Intentioner bag, anvendelse og virkning af evaluering i erhvervsuddannelserne [Evaluation Practice of Vocational Schools - Intentions Behind, Use and Effects of Evaluation in Vocational Education and Training]." PhD Thesis, Department of Learning and Philosophy, Aalborg University.

Hjort, Kathrine, and Steen Baagøe Nielsen. 2003. Mænd og omsorg [Men and Compassion]. København: Hans Reitzels Forlag.

Hollows, Joanne, and Steve Jones. 2010. “'At Least He’s Doing Something’: Moral Entrepreneurship and Individual Responsibility in Jamie's Ministry of Food.” European Journal of Cultural Studies 13: 307-322. www.sagepublications.com.

Jørgensen, Christian Helms, ed. 2013. Drenge og maskuliniteter i ungdomsuddannelserne [Boys and Masculinities in Upper Secondary Education]. Roskilde: Roskilde Universitetsforlag.

Jørgensen, Christian Helms, and Ida Juul. 2010. Bedre samspil mellem skolepraktik og ordinær virksomhedspraktik [Relations between School Apprenticeship and Ordinary In-company Apprenticeship]. Copenhagen: Danish Ministry of Education.

Køkken Hotel \& Restaurant Uddannelse. 2014. Gastronom med speciale kok, smørrebrødsjomfru og cater - uddannelse og job [Training and Job for Chef, Open Sandwich Assistant and Cater]. Copenhagen. www.khru.dk.

Lave, Jean, and Etienne Wenger. 1991. Situated Learning. Cambridge: Cambridge University Press.

Leer, Jonathan. 2013. "Madlavning som maskulin eskapisme - en analyse af madlavning og maskulin identitet i madprogrammerne The Naked Chef og Spise med Price [Cooking as Masculine Escapism - An Analysis of Cooking and Male Identity in the Television Programs The Naked Chef and Dining With Price]." Norma Nordic Journal for Masculinity Studies 8 (1): 42-57.

Mac an Ghaill, Máirtín. 1994. The Making of Men: Masculinities, Sexualities and Schooling. Buckingham: University Press.

Weinestål, Anneli Häyrén, Fredrik Bondestam, and Henrik Berg. 2011. Från novis til nestor. Maskulinitet, organisation och risk i räddningstjänsten - en aktionsforskningsstudie [From Novice to Master. Masculinity, Organization and Risk in Rescue Service]. Uppsala: Uppsala University, Centre for Gender Research. 